\title{
Challenges in the Management of Parathyroid Cyst: A Mini- review
}

\author{
Lynnette RL Tan ${ }^{1}$, Lau WL Joel ${ }^{2}$, James WK Lee ${ }^{3}$, Bengt Fredrik Petersson ${ }^{4}$, Rajeev Parameswaran ${ }^{5}$
}

\begin{abstract}
Parathyroid cysts are exceedingly uncommon but should remain a differential in the evaluation of a patient with a cystic neck lump. Case reports in the literature are few and far between and there are no universally defined guidelines as to the diagnosis and management of this condition. In this paper, we review the existing literature regarding the epidemiology, etiology, and clinical presentation of parathyroid cysts. We evaluate the existing diagnostic modalities, discuss their benefits and limitations, and discuss key considerations in the management of this little-known condition.

Keywords: Cyst, Hyperparathyroidism, Parathyroid.

World Journal of Endocrine Surgery (2021): 10.5005/jp-journals-10002-1312
\end{abstract}

The paired parathyroid glands were discovered by the medical student, Ivor Sandstrom in 1880. ${ }^{1}$ These glands secrete parathyroid hormone (PTH), which regulates the serum calcium by its action on bones, kidneys, and the gut. Pathological enlargement of the parathyroid glands due to an adenoma, hyperplasia, or carcinoma cause primary hyperparathyroidism. However, a clinician will on rare occasions, come across the uncommon entity called a parathyroid cyst. Parathyroid cysts account for only $0.5 \%$ of parathyroid lesions with 350 cases reported in the literature. ${ }^{2,3}$ In this review, we discuss the challenges in the diagnosis and management of parathyroid cysts.

Parathyroid cysts occur more commonly in the fourth and fifth decades of life and have a female preponderance. ${ }^{2}$ They are postulated to arise from the vestigial remnants of the third and fourth branchial clefts, ${ }^{4}$ persistence of the Kürsteiner canals of the fetal parathyroids, ${ }^{5}$ the cystic degeneration of an adenoma, ${ }^{6}$ or the aggregation of microcysts. ${ }^{2}$ They are most commonly located in the neck in the inferior parathyroid glands, ${ }^{7}$ or in the mediastinum, ${ }^{7,8}$ though occasionally are intra-thyroidal. ${ }^{9}$ The incidence appears to be higher in women in a ratio of 3:1 and more commonly in the middle age, and rarely seen in children. ${ }^{2}$

Parathyroid cysts present in many ways. Patients may be completely asymptomatic, learning of this finding during imaging procedures for other indications. When seen incidentally on imaging, they are usually seen on the left side and may be seen to be confused with a thyroid nodule or cyst. ${ }^{10}$ Symptoms vary with the size and location of the lesion. Large, centrally located mediastinal cysts may cause compressive symptoms. ${ }^{11}$ Hyperfunctioning cysts which secrete PTH may present with hypercalcemic symptoms including bone pain, gastrointestinal, and neurological symptoms. ${ }^{12,13}$ The incidence of parathyroid cysts in MEN 1 has shown to be around $4 \% .^{14}$

Because parathyroid cysts are uncommon, there is a lack of guidelines on their diagnosis and management. There are no pathognomonic findings on history and clinical examination. Neck masses are palpable only when sizeable and even then, are difficult to distinguish from thyroid lesions. Ancillary investigations that can help obtain a diagnosis include the following.
${ }^{1-3}$ Department of Endocrine Surgery, National University Health System, Singapore

${ }^{4}$ Department of Pathology, Yong Loo Lin School of Medicine, Singapore ${ }^{5}$ Department of Endocrine Surgery, National University Health System, Singapore; Department of Surgery, Yong Loo Lin School of Medicine, Singapore

Corresponding Author: Rajeev Parameswaran, Department of Endocrine Surgery, National University Health System, Singapore; Department of Surgery, Yong Loo Lin School of Medicine, Singapore, Phone: +6567724229, e-mail: rajeev_parameswaran@nuhs.edu.sg

How to cite this article: Tan LRL, Joel LWL, Lee JWK, et al. Challenges in the Management of Parathyroid Cyst: A Mini-review. World J Endoc Surg 2021;13(1):20-23.

Source of support: Nil

Conflict of interest: None

\section{LABORATORY TESTS}

Serum iPTH and calcium levels should be checked in all suspected parathyroid lesions to assess functional status. However, this does not indicate if the lesion is solid or cystic. FNA is increasingly performed with promising safety profiles. Parathyroid cysts classically yield "water-clear" aspirates; straw-colored fluid suggests a thyroid cyst and brown/hemorrhagic fluid occurs in parathyroid adenomas. Aspiration of the parathyroid cysts have generally a higher level of PTH and helps differentiate from a thyroid nodule, ${ }^{15,16}$ and other cystic lesions of the neck such as branchial cyst and esophageal duplication cyst. Serum iPTH levels, however, do not correlate with the size of the lesion, unlike in adenomas.

Microscopically, parathyroid cysts have a smooth inner surface wall with membranous lining, a single layer of cuboidal epithelium, and parathyroid tissue within the cyst wall (Figs 1 and 2). Atypical parathyroid cystic adenomas may mimic parathyroid carcinoma and it is important to look for vascular and capsular invasion in the submitted specimen to differentiate the two. ${ }^{17}$ Sometimes heterotopic salivary gland tissue may be seen around the cyst. ${ }^{18}$

(c) The Author(s). 2021 Open Access This article is distributed under the terms of the Creative Commons Attribution 4.0 International License (https://creativecommons. org/licenses/by-nc/4.0/), which permits unrestricted use, distribution, and non-commercial reproduction in any medium, provided you give appropriate credit to the original author(s) and the source, provide a link to the Creative Commons license, and indicate if changes were made. The Creative Commons Public Domain Dedication waiver (http://creativecommons.org/publicdomain/zero/1.0/) applies to the data made available in this article, unless otherwise stated. 


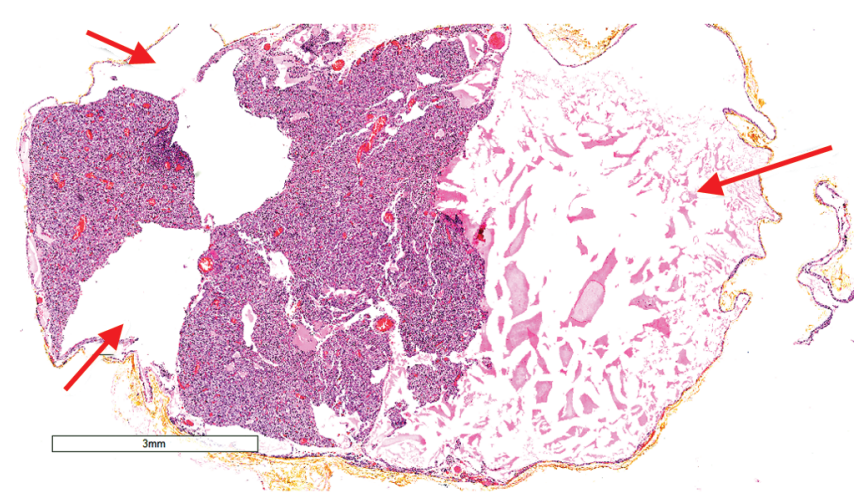

Fig. 1: Microscopy showing the parathyroid with cystic component

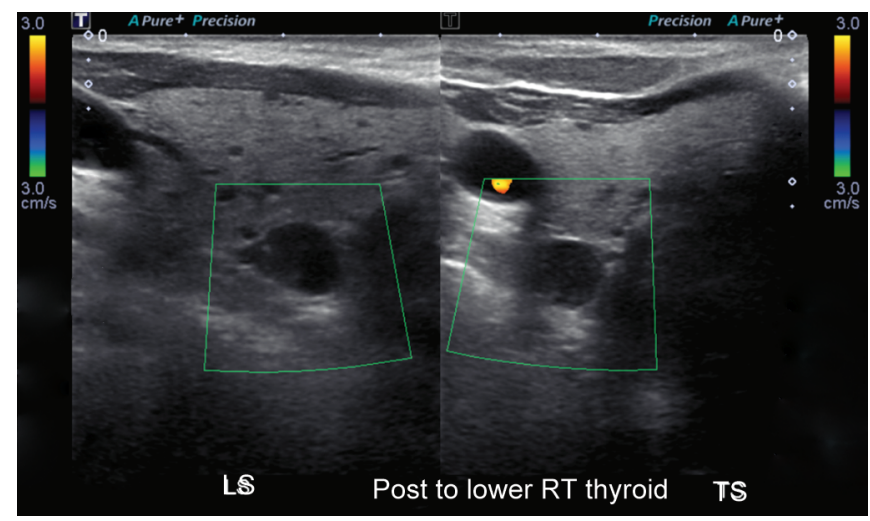

Fig. 3: US showing the cystic parathyroid at the postero-inferior pole of the thyroid

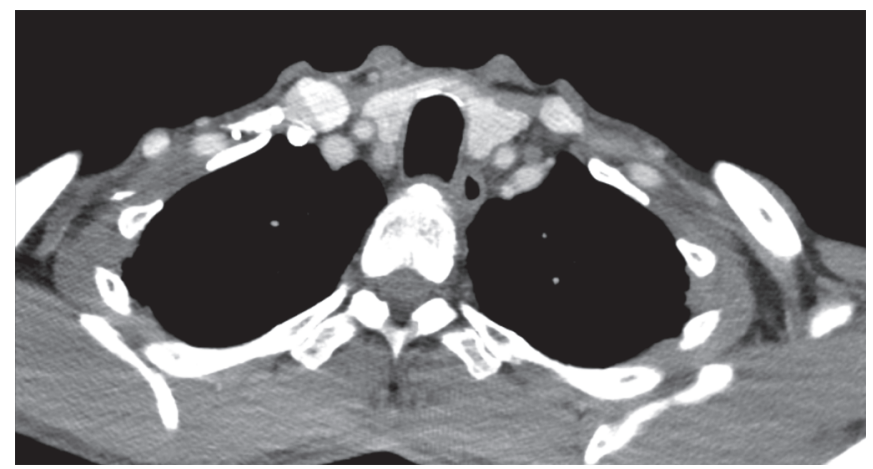

Fig. 5: CT scan of the same patient showing the parathyroid lesion at the inferior pole of the thyroid

\section{IMAGING}

Ultrasonography (US) is non-invasive, inexpensive, and often the first-choice option. ${ }^{19}$ Parathyroid cysts are usually posterior and/or inferior to the thyroid (Fig. 3), are hypoechoic and hypervascular with a prominent polar feeding vessel from a branch of the inferior thyroid artery. Ultrasonography demonstrates the anatomical relation of the parathyroid cyst to other neck structures and is useful intraoperatively when prior neck surgery creates a scarred surgical field making the location of the parathyroid cyst challenging. However, accuracy is reduced in inexperienced hands, in obese patients, and cysts that are smaller or located in the mediastinum posterior to the clavicles. ${ }^{20}$

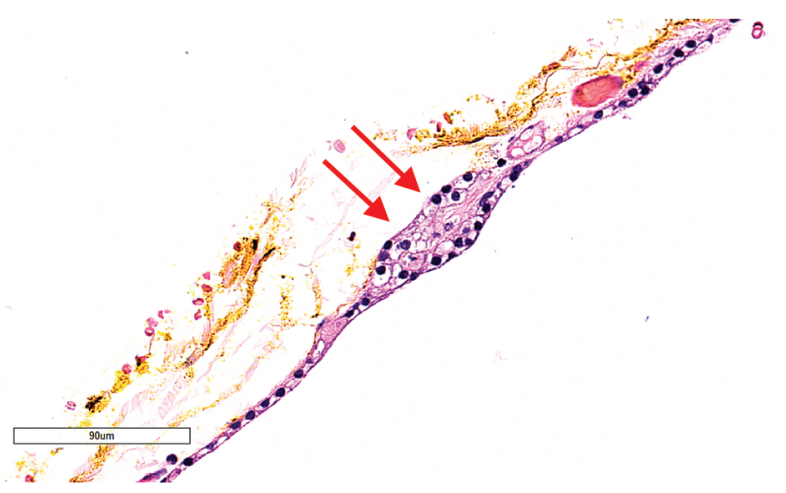

Fig. 2: High microscopy showing a parathyroid cyst with a smooth inner surface wall with membranous lining, a single layer of cuboidal epithelium

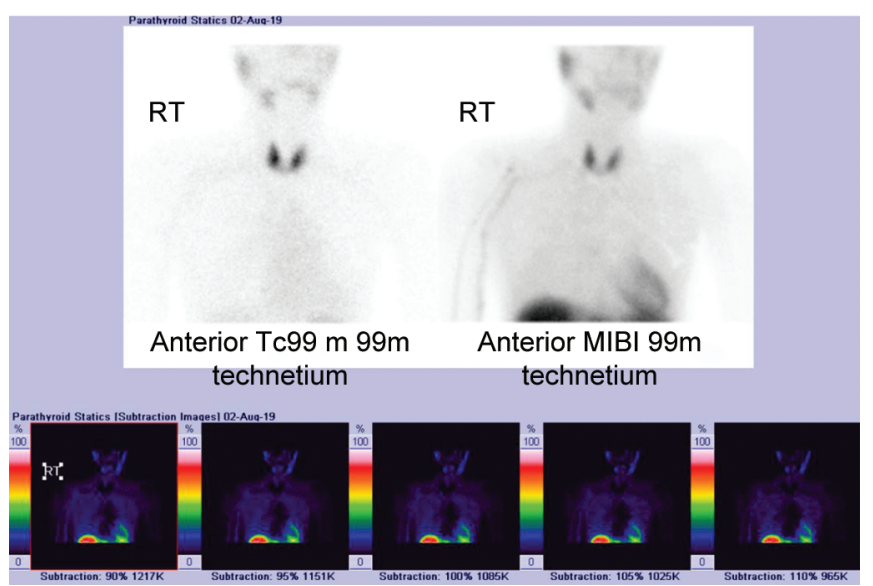

Fig. 4: Negative Technitium Sestamibi scan imaging along with SPECT for the same patient

99mTc-MIBI works based on radiotracer uptake and retention by mitochondria-rich oxyphil cells in parathyroid glands ${ }^{21}$ but is associated with significant false-negative rates particularly in small, superiorly located glands ${ }^{22}$ and parathyroid cysts (containing fewer oxyphil cells) (Fig. 4). ${ }^{23}$

In contrast, 4D-CT with volume-rendering reconstruction has statistically significant higher positivity and accurate localization rates. ${ }^{24}$ Parathyroid cysts demonstrate less enhancement in the arterial phase and little washout in the delayed phase compared with adenomas (Fig. 5). 3D-reconstructed images help facilitate surgical planning. Radiation exposure $\longrightarrow 50$-times that of MIBI! with elevated long-term risk of developing head and neck cancers remains a significant deterrent, particularly in younger patients.

18F-fluorocholine positron emission tomography (FCh-PET) computed tomography has demonstrated excellent detection rates, sensitivity, and spatial resolution than conventional scintigraphy and $\mathrm{CT}^{25}$ It is advantageous in localizing small, hyperplastic parathyroid glands, regardless of their histopathological composition. ${ }^{26}$ However, FCh-PET is non-specific for parathyroid disease and false positives can occur in cases of malignancy and inflammation.

Magnetic resonance imaging (MRI) has no radiation and has evaluated parathyroid cysts with some success although comparative studies with other modalities are lacking. Modern MRI technology utilizes fast imaging tools such as time-resolved 
Flowchart 1: Classification of parathyroid cysts

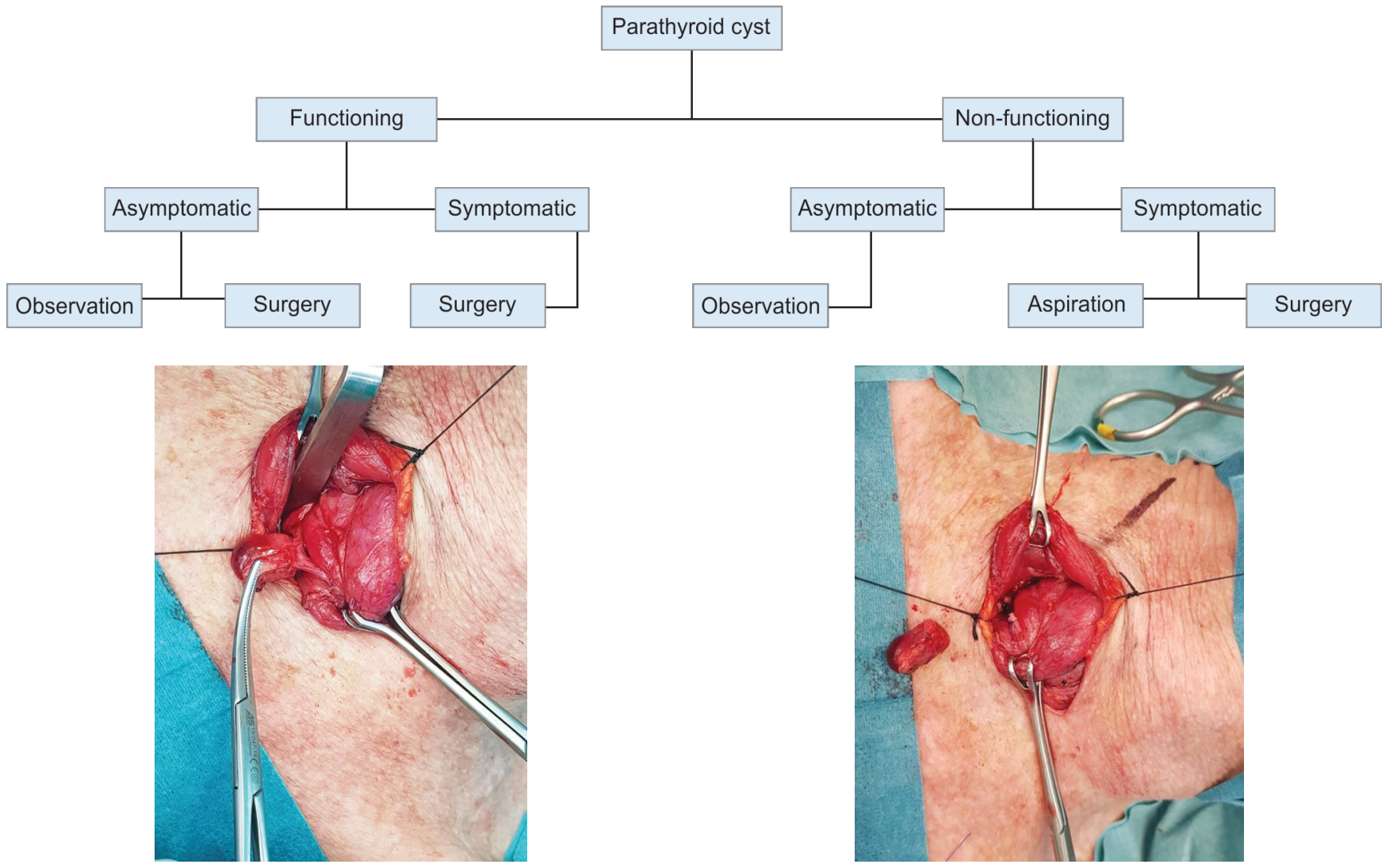

Fig. 6: Intraoperative image of the parathyroid cyst at the inferior pole of the thyroid on the right side

imaging with stochastic trajectories (TWIST), improved parallel imaging techniques, and fat-suppression techniques. ${ }^{27}$ Dynamic $4 \mathrm{D}$ contrast-enhanced MRI exploits the hypervascular nature of parathyroid lesions, distinguishing them from thyroid tissue and lymph nodes with good diagnostic accuracy. Although parathyroid cysts are less vascular, their fluid component yields a high T2WI signal that is easily detectable on MRI and this is an area that can be explored.

Our approach to the management of parathyroid cysts is outlined in Flowchart 1.

Treatment for asymptomatic functioning cysts is based on principles of management of primary asymptomatic hyperparathyroidism. Patients should be offered surgery if any of the criteria are fulfilled:

- Serum adjCa $>1 \mathrm{mg} / \mathrm{dL}$.

- $\quad T$-score $<-2.5$ on BMD.

- Vertebral fracture(s) on imaging.

- Renal impairment $(\mathrm{CrCl}<60 \mathrm{~mL} /$ minute).

- 24-hour urinary calcium $>400 \mathrm{mg} /$ day.

- Presence of nephrolithiasis/nephrocalcinosis on imaging.

The gold-standard treatment for symptomatic functioning cysts is surgery. Access depends on cyst characteristics. Most can be removed through a cervical incision (Figs 6 and 7) but larger mediastinal cysts may require thoracotomy or median sternotomy. ${ }^{28}$ Thoracoscopic $^{29}$ and robotic ${ }^{30}$ approaches have also been described. Care must be taken to avoid injury to the

Fig. 7: The excised parathyroid specimen in the same patient

ipsilateral recurrent laryngeal nerve, especially in large cysts. Cysts should ideally be removed intact or decompressed empirically to avoid spillage as there is a risk of parathyromatosis ${ }^{31}$ and recurrent hyperparathyroidism. Patients should be monitored closely for postoperative hypocalcemia; ${ }^{3}$ this generally occurs in those with larger cysts but all patients should have intravenous access and calcium replacement on standby nonetheless.

Patients with symptomatic non-functioning cysts should consider aspiration or surgery. Aspiration is less invasive, performed under local anesthetic, and a safer option in patients with comorbidities and high risk for general anesthesia. There is a risk of intra-cystic hemorrhage which can exacerbate hypercalcemia, and the possibility of recurrence. ${ }^{32,33}$ Sclerosing therapy with tetracycline and ethanol have been proposed to minimize recurrence, ${ }^{34,35}$ however, are associated with risks of peri-cystic fibrosis and damage to the recurrent laryngeal nerve. When carcinoma cannot be ruled out, FNA is discouraged because of the risk of malignant seeding along the percutaneous tract. ${ }^{36}$ Surgical resection can be considered if recurrences occur after repeated aspirations.

Patients with asymptomatic non-functioning cysts can be left alone. However, there is the possibility of cyst enlargement and symptom development over time, therefore patients should remain under follow-up, with repeat imaging and/or blood tests when clinically indicated. In a study of eight asymptomatic non-functional parathyroid cysts treated with aspiration, all of them recurred and eventually underwent surgery. ${ }^{33}$ 


\section{Conclusion}

Parathyroid cysts remain a rare entity. However, as diagnostic modalities continue to improve and existing practices are refined, we are optimistic that parathyroid cysts can be diagnosed with greater accuracy, and clearer guidelines on the management of parathyroid cysts will be developed in time to come.

\section{References}

1. Carney JA. The glandulae parathyroideae of Ivar Sandström. Contributions from two continents. Am J Surg Pathol 1996;20(9):11231144. DOI: 10.1097/00000478-199609000-00010.

2. Papavramidis TS, Chorti A, Pliakos I, et al. Parathyroid cysts: A review of 359 patients reported in the international literature. Medicine (Baltimore) 2018;97(28):e11399. DOI: 10.1097/MD.0000000000011399.

3. McCoy KL, Yim JH, Zuckerbraun BS, et al. Cystic parathyroid lesions: functional and nonfunctional parathyroid cysts. Archi Surg (Chicago 1960) 2009;144(1):52-56. DOI: 10.1001/archsurg.2008.531.

4. Wang C-A, Vickery ALJ, Maloof F. Large parathyroid cysts mimicking thyroid nodules. Ann Surg 1972;175(3):448-453. DOI: 10.1097/00000658-197203000-00020.

5. Kürsteiner W. Die Epithelkörperchen des Menschen in ihrer Beziehung zur Thyreoidea und Thymus. Anatomische Hefte 1898;11(3):391-459. DOI: $10.1007 /$ BF02109896.

6. Rogers L. Parathyroid cyst and cystic degeneration of parathyroid adenoma. Arch Pathol 1969;88(5):476-479.

7. Ippolito G, Ippolito G, Palazzo FF, et al. A single-institution 25-year review of true parathyroid cysts. Langenbeck's Archi Surg 2006;391(1):13-18. DOI: 10.1007/s00423-005-0579-y.

8. Kobayashi S, Karube $\mathrm{Y}$, Araki O, et al. A case of mediastinal parathyroid cyst: Review of 133 cases of mediastinal parathyroid cyst in the literature. Nihon Kokyuki Geka Gakkai zasshi (Kyoto, 1992) 2010;24(7):1041-1045.

9. Ahmad MM, Almohaya M, Almalki MH, et al. Intrathyroidal parathyroid cyst: an unusual neck mass. Clin Med Insights: Endocrinol Diabetes 2017;2017(10):1179551417698135. DOI: 10.1177/1179551417698135.

10. Ujiki MB, Nayar R, Sturgeon C, et al. Parathyroid cyst: often mistaken for a thyroid cyst. World J Surg 2006;31(1):60-64. DOI: 10.1007/s00268005-0748-8.

11. Wirowski D, Wicke $C$, Böhner $\mathrm{H}$, et al. Presentation of 6 cases with parathyroid cysts and discussion of the literature. Experiment Clin Endocrinol Diabetes 2008;116(8):501-506. DOI: 10.1055/s-20081058084.

12. Albertson DA, Marshall RB, Jarman WT. Hypercalcemic crisis secondary to a functioning parathyroid cyst. Am J Surg 1981;141(1):175-177. DOI: 10.1016/0002-9610(81)90033-7.

13. Gurbuz AT, Peetz ME. Giant mediastinal parathyroid cyst: an unusual cause of hypercalcemic crisis--case report and review of the literature. Surgery 1996;120(5):795-800. DOI: 10.1016/s0039-6060(96)80086-9.

14. Cavalli T, Cavalli T, Giudici F, et al. Cystic parathyroid glands in MEN1: a rare entity? Fam Cancer 2017;16(2):249-256. DOI: 10.1007/s10689016-9936-y.

15. Stoffer SS, Szpunar WE, Hawker CD. Differentiation of thyroid from parathyroid cysts. JAMA 1980;243(14):1422. DOI: 10.1001/ jama.1980.03300400012010.

16. Pacini F, Antonelli A, Lari R, et al. Unsuspected parathyroid cysts diagnosed by measurement of thyroglobulin and parathyroid hormone concentrations in fluid aspirates. Ann Intern Med 1985;102(6):793-794. DOI: 10.7326/0003-4819-102-6-793.

17. Wani S, Hao Z. Atypical cystic adenoma of the parathyroid gland: case report and review of literature. Endocr Pract 2005;11(6):389-393. DOI: 10.4158/EP.11.6.389.
18. Carney JA. Salivary heterotopia, cysts, and the parathyroid gland: branchial pouch derivatives and remnants. Am J Surg Pathol 2000;24(6):837-845. DOI: 10.1097/00000478-200006000-00009.

19. Johnson NA, Tublin ME, Ogilvie JB. Parathyroid imaging: technique and role in the preoperative evaluation of primary hyperparathyroidism. Am J Roentgenol 2007;188(6):1706-1715. DOI: 10.2214/AJR.06.0938.

20. Berber E, Parikh RT, Ballem N, et al. Factors contributing to negative parathyroid localization: an analysis of 1000 patients. Surgery 2008;144(1):74-79. DOI: 10.1016/j.surg.2008.03.019.

21. Palestro CJ, Tomas MB, Tronco GG, ed. Radionuclide imaging of the parathyroid glands. Semin Nucl Med. Elsevier; 2005. pp. 266-276.

22. Stephen $\mathrm{AE}$, Roth $\mathrm{SI}$, Fardo DW, et al. Predictors of an accurate preoperative sestamibi scan for single-gland parathyroid adenomas. Archi Surg 2007;142(4):381-386. DOI: 10.1001/archsurg.142.4.381.

23. McCoy KL, Ghodadra AG, Hiremath TG, et al. Sestamibi SPECT/ CT versus SPECT only for preoperative localization in primary hyperparathyroidism: a single institution 8-year analysis. Surgery 2018;163(3):643-647. DOI: 10.1016/j.surg.2017.10.064.

24. Kukar M, Platz TA, Schaffner TJ, et al. The use of modified fourdimensional computed tomography in patients with primary hyperparathyroidism: an argument for the abandonment of routine sestamibi single-positron emission computed tomography (SPECT). Ann Surg Oncol 2015;22(1):139-145. DOI: 10.1245/s10434-014-3940-y.

25. Boccalatte LA, Higuera F, Gómez NL, et al. Usefulness of $18 \mathrm{~F}$-fluorocholine positron emission tomography-computed tomography in locating lesions in hyperparathyroidism: a systematic review. JAMA Otolaryngol Head Neck Surg 2019;145(8):743-750. DOI: 10.1001/jamaoto.2019.0574.

26. Zajíčková K, Zogala D, Kubinyi J. Parathyroid imaging by (18) F-fluorocholine $\mathrm{PET} / \mathrm{CT}$ in patients with primary hyperparathyroidism and inconclusive conventional methods: clinico-pathological correlations. Physiol Res. 2018;67(Suppl 3):S551-S557. DOI: 10.33549/ physiolres.934029.

27. Nael K, Hur J, Bauer A, et al. Dynamic 4D MRI for characterization of parathyroid adenomas: multiparametric analysis. Am J Neuroradiol 2015;36(11):2147-2152. DOI: 10.3174/ajnr.A4425.

28. Shields TW, Immerman SC. Mediastinal parathyroid cysts revisited. Ann Thora Surg 1999;67(2):581-590. DOI: 10.1016/s00034975(99)00018-1.

29. Dell'Amore A, Asadi N, Bartalena T, et al. Thoracoscopic resection of a giant mediastinal parathyroid cyst. Gen Thora Cardiovascu Surg 2014;62(7):444-450. DOI: 10.1007/s11748-013-0256-y.

30. Go P, Watson J, Lu Z, et al. Robotic resection of a mediastinal parathyroid cyst. Gen Thora Cardiovascu Surg 2017;65(1):52-55. DOI: 10.1007/s11748-015-0587-y.

31. Hage MP, Salti I, Fuleihan GE-H. Parathyromatosis: a rare yet problematic etiology of recurrent and persistent hyperparathyroidism. Metabolism 2012;61(6):762-775. DOI: 10.1016/j.metabol.2011.11.001.

32. Shi B, Guo H, Tang N. Treatment of parathyroid cysts with fine-needle aspiration. Ann Int Med 1999;131(10):797-798. DOI: 10.7326/00034819-131-10-199911160-00035.

33. Rossi ED, Revelli L, Giustozzi E, et al. Large non-functioning parathyroid cysts: our institutional experience of a rare entity and a possible pitfall in thyroid cytology. Cytopathology 2015;26(2):114-121. DOI: 10.1111/cyt.12153.

34. Fortson JK, Patel VG, Henderson VJ. Parathyroid cysts: a case report and review of the literature. Laryngoscope 2001;111(10):1726-1728. DOI: 10.1097/00005537-200110000-00010.

35. Prinz R, Peters J, Kane J, et al. Needle aspiration of nonfunctioning parathyroid cysts. Am Surg 1990;56(7):420-422.

36. Kim J, Horowitz G, Hong M, et al. The dangers of parathyroid biopsy. J Otolaryngol Head Neck Surg 2017;46(1):4. DOI: 10.1186/s40463-0160178-7. 